\title{
EXPERIMENTAL AND NUMERICAL ASSESSMENT OF A LAST STAGE ST BLADE DAMPING AT LOW LOAD OPERATION
}

\author{
Andrea Bessone ${ }^{a, *}$, Luigi Carassale ${ }^{b}$, Roberto Guida ${ }^{b}$, ZdenĚK Kubín ${ }^{c}$, \\ Antonio Alfio Lo Balbo ${ }^{a}$, Michela Marrè Brunenghi ${ }^{a}$, \\ LORENZO PINELLI ${ }^{d}$
}

${ }^{a}$ Ansaldo Energia, Via N.Lorenzi 8, 16152 Genova, Italy

${ }^{b}$ University of Genoa, Via Balbi 5, 16126 Genova, Italy

c Doosan Škoda Power, Tylova 1/57, 30128 Pilsen, Czech Republic

$d$ University of Florence, Piazza San Marco 4, 50121 Florence, Italy

* corresponding author: andrea.bessone@ansaldoenergia.com

\begin{abstract}
As LP steam turbines are requested to work at strong part-loads, LSB stalled and unstalled flutter may occur. Testing on a downscaled steam turbine in T10MW test plant have been carried out to measure LSB aggregated damping at low load. Also numerical analysis to predict aerodynamic damping have been performed and results have been compared to experimental data, allowing software tool validation at low load.
\end{abstract}

KEYWORDS: Low pressure steam turbine blade, flutter, low load operation.

\section{INTRODUCTION}

Due to the increasing share of unpredictable and floating renewable production on the energy markets, gas and steam turbines are requested to operate at strong off-design conditions, in order to fulfill the residual demand.

Within this framework, it is mandatory that the last stage steam turbine blades operate at strong part loads, where flow-structure interaction may result in aero-elastic instabilities such as unstalled and stalled flutter, leading to asynchronous blade vibrations and possible blade failures for high cycle fatigue.

This happens in case the aggregated blade damping (which consists of a mechanical and aerodynamic contribution) is not sufficient to suppress blade vibrations as theseoccur. To this end, flutter is a quite well known phenomenon at design conditions.

Many documents in literature are available [1 5] showing that the aerodynamic damping prediction is possible and reliable enough when the steady flow field on the blade is as designed.

On the other hand, there is a much lower confidence on the aerodynamic behavior as the blade is operated at strong part load conditions. In this case, the aerodynamic load on the airfoil is characterized by off-design incidence angles leading to flow separations, affecting the flow-structure interaction and, consequently, the aerodynamic damping.

Numerical methods for blade damping estimation require the computation of the unsteady pressure response caused by the row vibration. They are usually classified in time-linearized, harmonic balance and non-linear approach both in frequency and time domain [4, 6, 7]. The validation of all these methods firstly started in the branch of low pressure turbines for aviation [3, 8] and has been gradually extended to compressor blades and steam turbine rows [9]. For the analysis of steam turbine last rotor operating at strong part load conditions, non-linear approaches turns out to be recommended as this method is able to deal with non-linear phenomena as shock waves and wide flow separations.

Within the present work, a downscaled 3-stages low pressure steam turbine has been designed by AEN and tested at the DSPW T10MW test facility. The turbine operates in wet steam environment and runs in analogy with a real scale steam turbine. The main aim of the tests has been to measure both the steady flow field within the last stage turbine blade, as it is operated at strong part load and the overall damping of the blade itself. Aggregated damping measurements have been done exciting the blade resonances by means of an electromagnetic excitation, induced by an AC magnet mounted on the vane carrier. Furthermore, the mechanical and the aerodynamic contributions to the overall damping have been estimated.

The data will be used to validate unsteady CFD analysis to predict aerodynamic damping in terms of logarithmic decrement: numerical results have been achieved through an upgraded version of CFD software tool, optimizing numerical settings for simulation of very low load conditions, such as increased condenser pressure. 


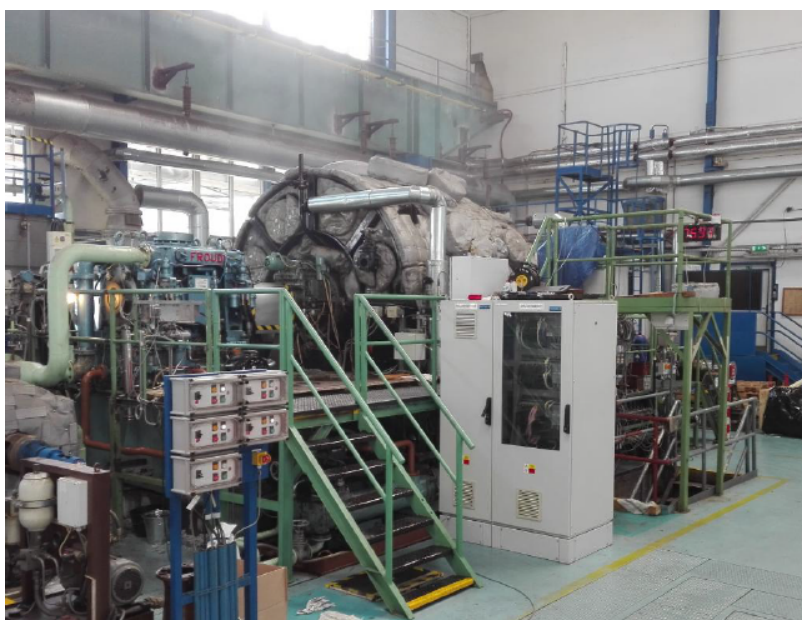

Figure 1. T10MW steam turbine test rig in Plzen, CZ.

\section{EXPERIMENTAL SETUP AND DAMPING MEASUREMENT TECHNIQUE}

\subsection{DownSCALED LOW PRESSURE STEAM TURBINE TESTED ON T10MW TEST RIG}

Tests have been carried out in the T10MW test facility located in the DSPW's experimental laboratory in Plzen $(\mathrm{CZ})$. A view of the facility is provided in Fig.1 The experimental apparatus consists of a threestages LP steam turbine designed and manufactured by AEN whithin the FT project. The LSB is downscaled from a 37 inches height blade mounted on a real turbine, with a part-span snubber and without any tip shroud. Similarity criteria have been adopted to correctly reproduce the same aerodynamic, mechanical and aero-elastic behavior of the full-size machine, in order to experimentally characterize the flutter behavior of the last stage blade.

The geometrical similarity of the test turbine with respect to the full-scale machine is respected. A scale factor of about 0.4 has been adopted, resulting the best compromise for testing the widest range of operating conditions within the DSPW T10MW test rig capabilities (in terms of vacuum pressure and mass flow rate).

The aerodynamic similarity is achieved by keeping constant the reduced speed defined as in eq.1 and the same LPT expansion line.

$$
N_{\text {rid }}=\frac{N D}{\sqrt{p_{0} v_{0}}}
$$

where $p_{0}$ and $v_{0}$ are respectively pressure and specific volume of the steam at the turbine inlet.

Consequently, flow velocities and Mach numbers are kept equal to the full scale turbine. Hence, the aerodynamic loading on the airfoils is the same.

The Reynolds number scales by the geometrical scale factor, but its effect on this study can be considered as negligible.
LSB have been manufactured with the same material as the full scale ones. Hence, since the geometrical similarity is respected, the stresses and mode shapes remain unchanged, while the modal frequencies are up-scaled by the geometrical scale factor. As a consequence, the aero-elastic behavior is reproduced through the similarity of the Strouhal number, which represents the ratio between the time taken by the flow to cross the blade channel and the time characterizing a vibration period, as in equation 2

$$
S t=\frac{f^{\prime} \cdot C h^{\prime}}{v_{\text {out }}^{\prime}}=\frac{\left(\frac{D}{D^{\prime}}\right) f \cdot\left(\frac{D^{\prime}}{D}\right) C h}{v_{\text {out }}}
$$

where the quantities with prime refer to the downscaled blade, the others to the fullscaled one. Rotor blade tip gaps, sealing flows and manufacturing tolerances are not scaled. Anyway, these aspects are properly considered within the numerical analysis and their effects quantified. Therefore, experimental data are consistent with the full size machine.

The test facility adopts steam as working fluid, allowing to reproduce condensation in the last LPT stages. This enables to follow the influence of the liquid phase on the thermodynamic efficiency of the stages. Hence, the experimental turbine gives the possibility to study the effects connected to the wet steam flow. The performance on the stage or on the group of stages is measured by using the water brake Froude (maximum revolutions $8000 \mathrm{rpm}$, the brake performance is $10 \mathrm{MW}$ ). A dynamometer system may be used for lower turbine power instead of the brake. The maximum flow rate of the steam through the turbine is $80 \mathrm{t} /$ hour. The inlet pressure may be up to 15 bar.

Two different test conditions, named OP3 and OP8, are studied in the following. The main operating parameters of the two OPs are summarized in table 1. They are characterized by different mass flow rates and vacuum pressures, but same volumetric flow rate at the turbine exit. According to the similarity criteria previously described, this means that the aerodynamic loading on the LSB is the same for both the OPs. The last stage blade specific power is approximately nihil because, at these levels of volumetric flow rate, ventilation occurs and the flow does not expand through the blade channel anymore. Moreover, at this volumetric flow rate, the last stage blade operates in subsonic conditions with off-design incidence. This condition is evident looking at Fig. 2 where the blade aerodynamic loading, calculated through TRAF 3D FNS CFD solver, are shown in terms of iso-Mach distribution on the airfoil at three different span sections.

\subsection{Steam turbine instrumentation and SG POSITIONING}

LPT has been instrumented with more than 70 measurement points aiming to characterize the LSB flutter behavior in a wide range of working conditions. 


\begin{tabular}{cccc}
\hline & $\begin{array}{c}\text { Steam mass flow } \\
(\mathrm{kg} / \mathrm{s})\end{array}$ & $\begin{array}{c}\text { Condenser pressure } \\
(\mathrm{bar})\end{array}$ & $\begin{array}{c}\text { Volume flow LSB TE } \\
\left(\mathrm{m}^{3} / \mathrm{s}\right)\end{array}$ \\
\hline OP3 & 13.7 & 0.213 & $\approx 90$ \\
OP8 & 17.6 & 0.280 & $\approx 90$ \\
\hline
\end{tabular}

TABLE 1. The main operating parameters of the OP3 and OP8.
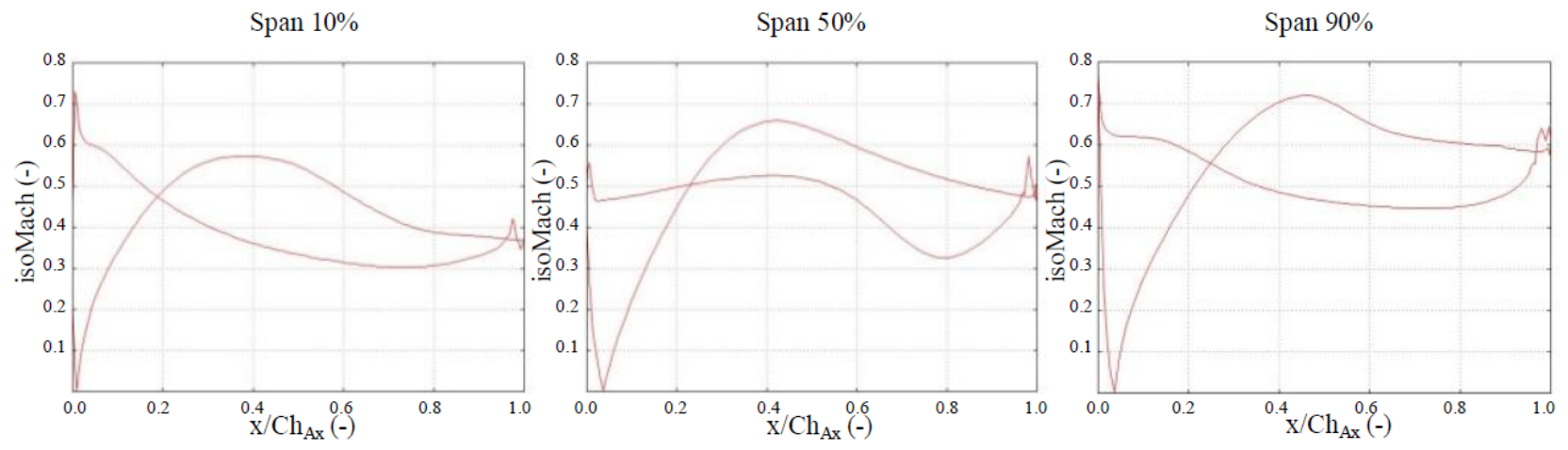

Figure 2. OP3 and OP8 operating parameters and last stage blade loading at $10 \%, 50 \%$ and $90 \%$ span for the analyzed volume flow.

Flutter response of the blade is strongly dependent on the flow conditions resulting from the upstream rows and on the pressure distribution at the turbine outlet. For this reason, beside the dynamic measurements to characterize blade vibration such as BTT and SG, time averaged flow quantities have been recorded too: the expansion line has been measured, as well as radial distributions of flow variables at the turbine inlet and downstream the last rotor blade trailing edge. In particular, a rake of 5-hole probes has been installed downstream of the last stage blade trailing edge in order to measure the radial distribution of the total and static pressure and flow angles. This also allows the definition of the aerodynamic load of the blade during ventilation and the height of the flow separation at the hub.

Fig. 3 shows the ST meridian view with the qualitative positioning of the sensors is reported. Different symbols correspond to different types of sensors (see the table on the right). The sensors are also distributed in the circumferential direction to evaluate the uniformity of the flow, since flow axial-symmetry is the underlying assumption for numerical analyses described in the next chapter.

Strain gauges have been positioned in order to measure the best possible response of the last blade in terms of amplitude of vibration. The choice was based on the results of the FE modal analysis of the component, taking into account the most reliable zone for the strain gauges wiring: the area above the fillet between the airfoil and the platform. Two strain gauge optimal locations have been identified and four blades have been instrumented, as reported in Fig. 4 . Furthermore, the last blade has been instrumented by directional strain gauges, in particular positioned in the radial direction.
The strain gauges positioning is based on FE analyses at design operating condition, at a nominal speed of $7600 \mathrm{rpm}$. In Fig. 5 the radial deformations along the suction side of the airfoil, at a radius just above the fillet between the airfoil and the platform, are reported. Normalized deformations are shown for the first five vibration modes. The final position of the strain gauges was identified as the best compromise allowing to measure dynamic response for the most relevant mode shapes.

\subsection{DAMPing MEASUREMENT TECHNiqUE: MAGNET SETUP AND SWEEP METHOD}

Because of the turbine control system limitation, it is not possible to accurately hold the turbine rotor at constant speed (rpm). This limitation is unpleasant due to the excitation of blades natural frequency on specific nodal diameters. The excitation of rotating blades is usually carried out by an electromagnet and an oscillator, assuming a constant rpm. Therefore, it is necessary to use another excitation approach, some type of a dynamic excitation that accepts turbine speed fluctuation. The magnet excitation voltage signal is given by the formula:

$$
y_{m}(t)=A \cdot \sin \left(2 \cdot \pi \cdot f_{\text {ext }} \cdot t\right)+D C
$$

where DC is direct voltage component used to shift the excitation signal to be symmetrical ( \pm amplitude $[\mathrm{V}])$ and $f_{\text {ext }}$ is the excitation frequency of the magnet needed to induce blades vibration at the calculated natural frequency. The magnet excitation frequency $f_{\text {ext }}$ is given by the formula:

$$
f_{\text {ext }}(t)=f_{b} \pm N D \cdot f_{\text {rot }}(t)
$$

where $f_{b}$ is the calculated natural frequency of the blades, $N D$ is the number of nodal diameters of the selected mode and $f_{\text {rot }}(t)$ is the turbine speed. Since the 


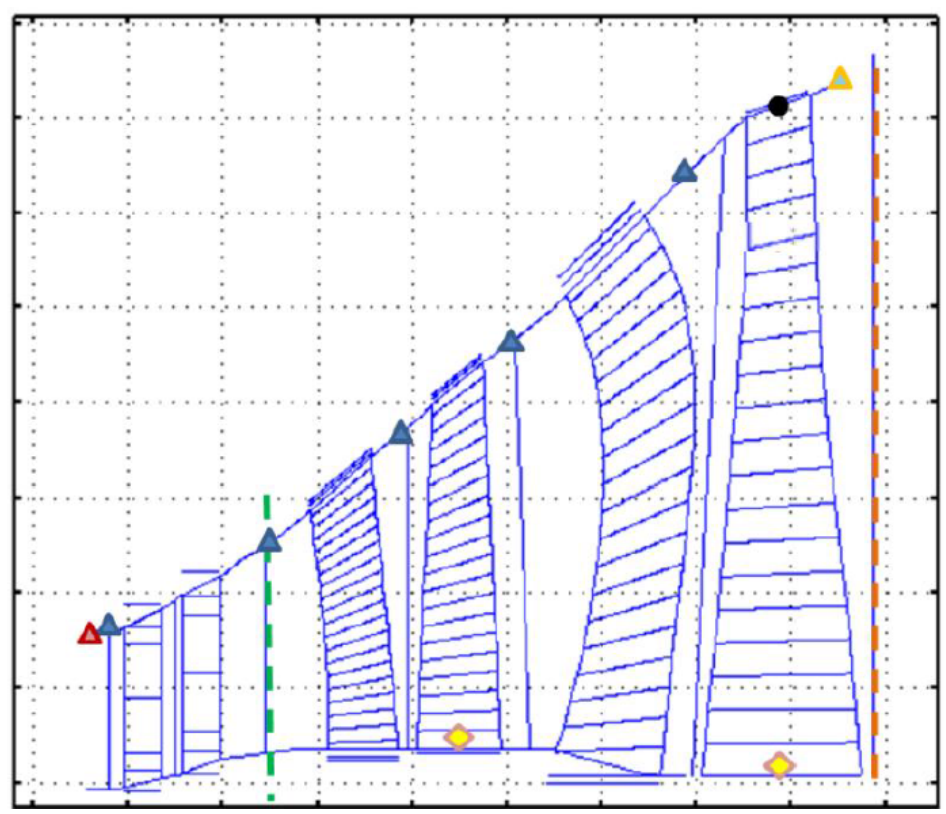

\begin{tabular}{|c|c|c|c|c|}
\hline Symbol & $\begin{array}{l}\text { Instrument } \\
\text { type }\end{array}$ & $\begin{array}{l}\frac{\text { Time }}{\text { Averaged/High }} \\
\text { Freq. Sampling }\end{array}$ & Location & 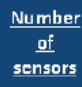 \\
\hline$\Delta$ & $\begin{array}{c}\text { Static pressure } \\
\text { probes }\end{array}$ & Slow & $\begin{array}{l}\text { Casing: } 3 \text { in } \\
\text { circumferential direction } \\
\text { for } 5 \text { axial postions }\end{array}$ & 15 \\
\hline$\Delta$ & Thermocouple & Slow & Casing: 1 at turbine inlet & 1 \\
\hline 0 & $\mathrm{BTT}$ & Fast & $L-0$ & 8 \\
\hline$\diamond$ & SE & \multirow{3}{*}{ Fast } & L-0 & 8 \\
\hline \multirow[t]{2}{*}{ 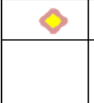 } & SG & & $L-1$ & 4 \\
\hline & $\begin{array}{l}\text { Telemetry } \\
\text { system }\end{array}$ & & Rotor & - \\
\hline$\Delta$ & $\begin{array}{l}\text { Kulite probe } \\
\text { (hi gh freq } \\
\text { pressure } \\
\text { measurement) }\end{array}$ & Fast & $\begin{array}{l}\text { Turbine casing } \\
\text { downstream L- } 0 \text { TE: } 6 \text { in } \\
\text { circumferential direction }\end{array}$ & 6 \\
\hline$=--$ & T0, p0 rakes & Slow & $\begin{array}{l}\text { Second stage inlet, } \\
\text { downstream L-2 TE: } 2 \text { in } \\
\text { circumferential direction, } \\
5 \text { different span-wise } \\
\text { positions for p } 0-1 \text { for TO }\end{array}$ & $\begin{array}{c}12 \\
(10 \times \mathrm{PO} \\
+2 \times \mathrm{TO} 0\end{array}$ \\
\hline$=--$ & $\begin{array}{l}\text { 5-hole -probe } \\
\text { rake for flow } \\
\text { angle } \\
\text { measurement }\end{array}$ & Slow & $\begin{array}{c}\text { Steam turbine outlet, } \\
\text { downstream L-םTE: } 1 \text { in } \\
\text { circumferential direction, } \\
5 \text { different span-wise } \\
\text { positions }\end{array}$ & 25 \\
\hline
\end{tabular}

FiguRE 3. ST instrumentation.
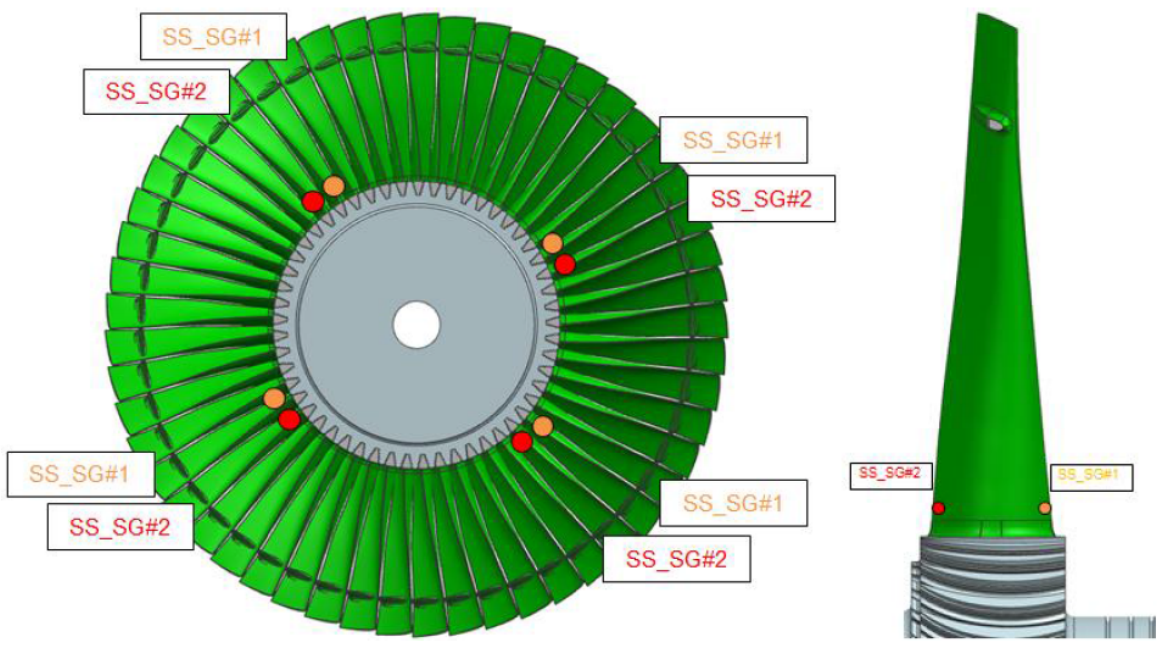

FIGURE 4. Strain gauges positioning on the last blade row.

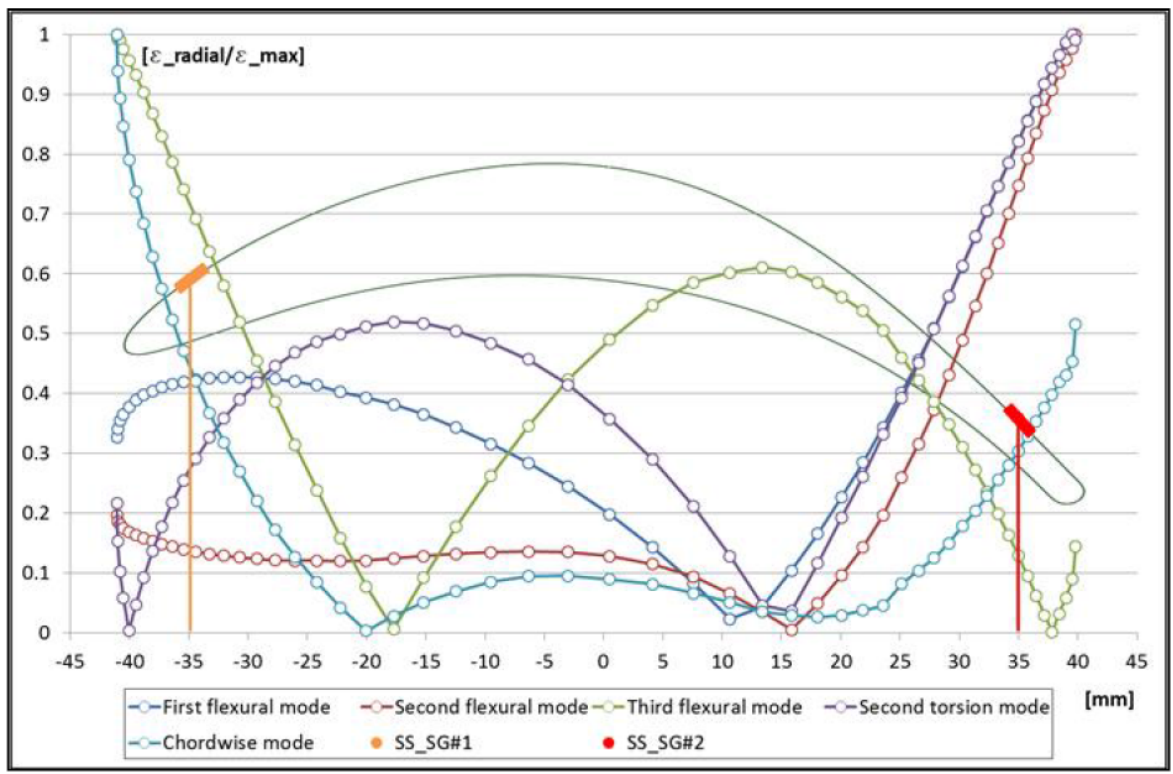

FIGURE 5. Normalized radial deformations on LSMB along the suction side of the airfoil. 


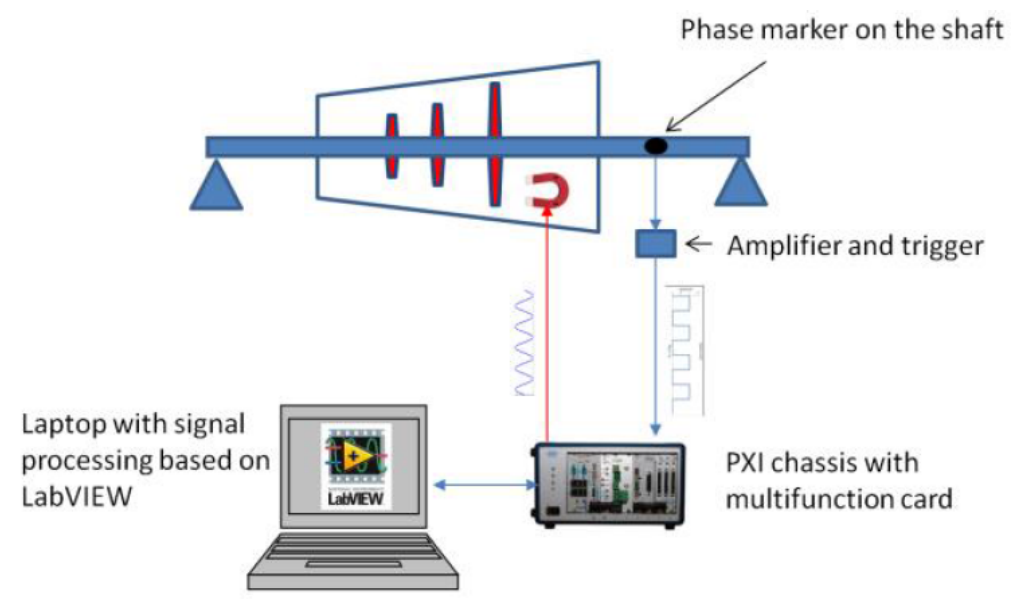

FiguRE 6. Measurement and magnet excitation diagram.

turbine speed is fluctuating, the excitation frequency of the magnet will also need to change.

Measurement and processing chain has been assembled. It consists of the turbine speed measurement and magnet excitation, which is evident from the diagram in Fig.6.

The analog signal from the phase marker (placed on the turbine rotor) is processed in an amplifier and in a trigger, which converts it into TTL pulses. TTL pulses continue to the multifunction card with counters (PXI6281 with 2 counters at $80 \mathrm{MHz}$ is used). TTL pulses are then processed in the laptop using LabVIEW code, where the instantaneous turbine rotor speed is calculated. From the actual speed of the turbine rotor, the magnet excitation frequency required to excite the blade eigenfrequency at the specific ND is calculated. The calculated frequency with given amplitude is sent via the analog output card to the magnet. The same multifunction card with two fast analog output channels is used. This is repeated until the excitation time expires (usually 100 seconds). At the excitation time, the calculated frequency is swept in a range, because it is slightly different from the real one. Sweep is usually $\pm 3 \mathrm{~Hz}$.

The measurement and magnet excitation algorithm (written in LabVIEW) is divided into two parallel branches. In the first branch, the magnet parameter setting is performed and it provides timing and sweeping of the excitation frequency. The second branch evaluates the turbine speed continuously and receives information about magnet parameters, timing and sweeping from the first branch. The magnet excitation frequency is then calculated and the excitation itself is performed. This is repeated until the excitation time expires. The diagram in Fig. 7 is illustrative of the abovementioned process flow.

\subsection{DAMPing MEASUREMENT TECHNIQUE: DAMPING ESTIMATION METHOD}

The blade total damping is estimated following the procedure proposed in Carassale et. al (2015) [10] in order to avoid the systematic overestimation due to the finite sweep frequency excitation. The method consists on extracting the Wavelet-based Frequency Response Function (W-FRF) of the system using the continuous wavelet transform (WT) of the blade response during the passage through resonance. See [11 and 12 for more details on the procedure and validation of the method.

The WT of a generic signal $g(t)$ with finite energy is given, according to eq. 5 , by correlating the function itself with a set of function $\psi(u, s)$ called wavelet atoms 13:

$$
W_{u, s}[g]=\frac{1}{\sqrt{s}} \int_{-\infty}^{\infty} g(t) \psi^{*}\left(\frac{t-u}{s}\right) d t
$$

where the superscript $*$ denotes the complex conjugate. The wavelet atoms are obtained by translating and scaling a prototype function with compact support, called mother wavelet $\psi(t)$, by a time shift $u$ and a scale factor $s$ as in eq. 5 . Hence, by construction, this set of functions is well defined in the time-frequency domain by the time $u$ and the central frequency $\eta=$ $\omega_{c} / s$, where $\omega_{c}$ takes the name of central (round) frequency and is a property of the mother wavelet.

The W-FRF is derived assuming that each blade acts as an independent LTV s-dof system. In this way, the natural frequency variation due to modification in the rotor speed has been taken into account. Hence the blade response $q(t)$ due to the magnet excitation $f(t)$ is governed by the following differential equation:

$$
m(t) q^{\prime \prime}(t)+c(t) q^{\prime}(t)+k(t) q(t)=f(t)
$$

where $m, c, k$ are the system properties and assumed to vary slowly with time. Applying the wavelet transform to the right and left sides of the equation, the following relationship is obtained:

$$
W_{u, s}[q]=H(u, s) W_{u, s}[f]
$$

where $H(u, s)$ is referred to as the Wavelet-based Frequency Response Function (WFRF). Fig.9 shows the continuous wavelet transform of the blade response 


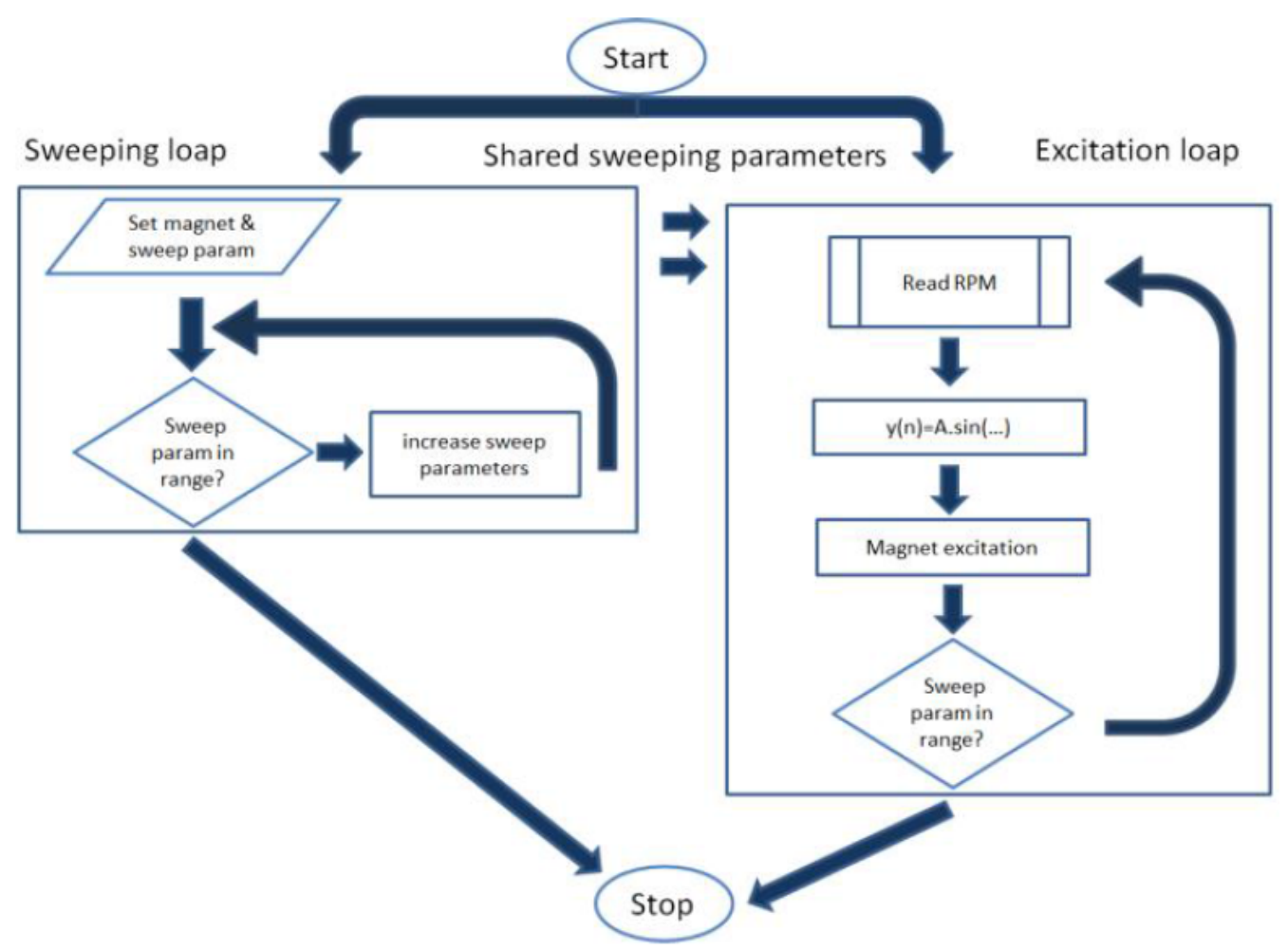

FiguRE 7. Measurement and excitation algorithm.

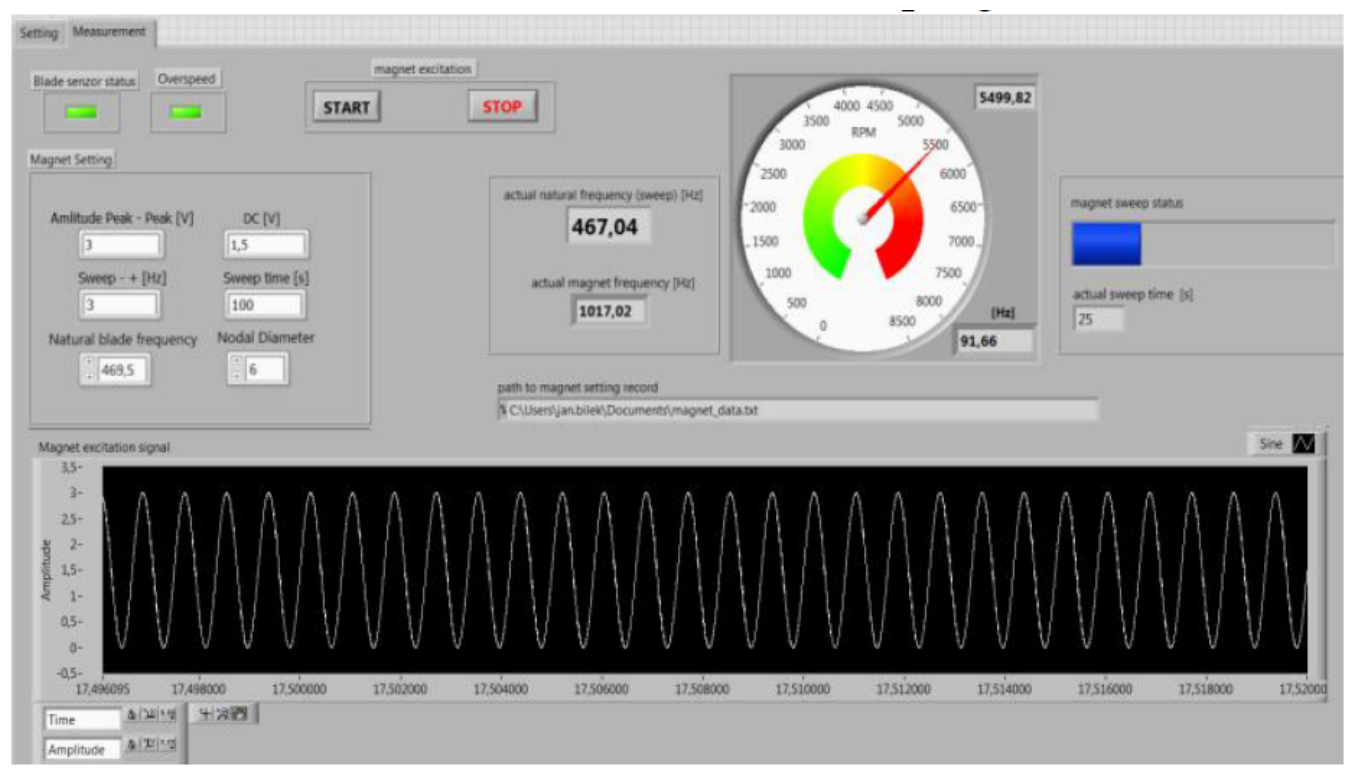

Figure 8. Measurement and excitation LabVIEW user interface. 


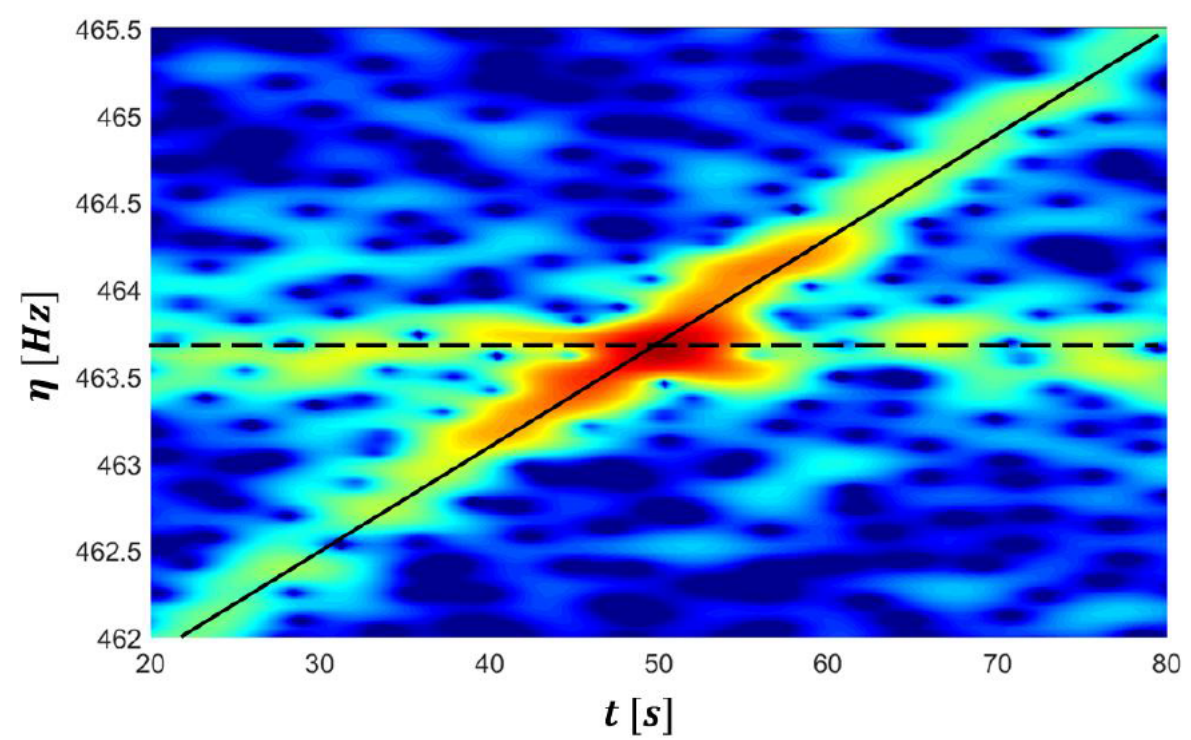

Figure 9. Continuous wavelet transform for first mode shape, $N D=4$, backward traveling wave.

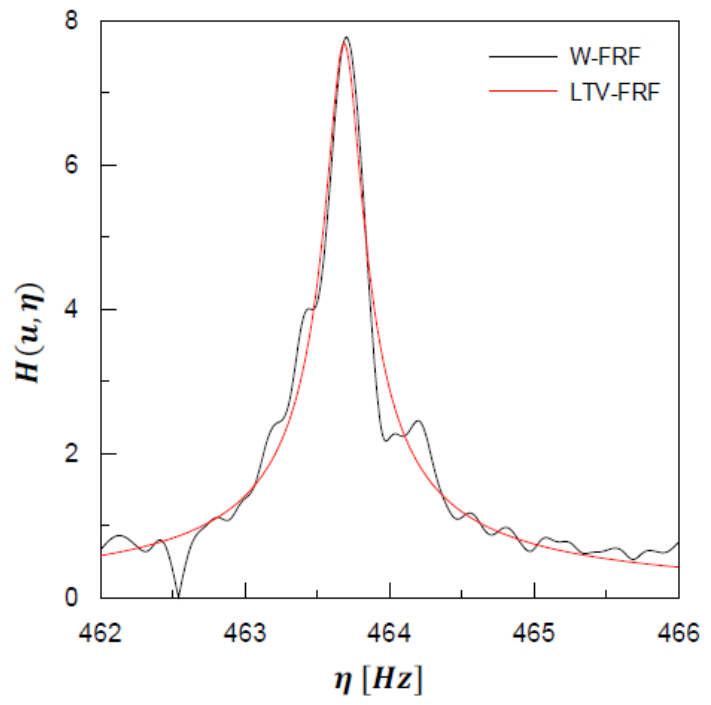

FiguRE 10. LTV-FRF best fitting of W-FRF.

$W_{u, s}[q]$ in the case when the magnet excites the nodal diameter -4 of the first mode. The dashed line highlights the blade eigenfrequency while the continuous black line fits the magnet excitation. Since the rotational speed is kept almost constant throughout the tests, the natural frequency shows a constant value either. When the magnet excitation crosses the natural frequency, around $t=50 \mathrm{~s}$ and $\eta=463.7 \mathrm{~Hz}$, a peak value of $W_{u, s}[q]$ is observed which denotes the blade resonance.

Furthermore, the system parameters can be obtained by fitting the W-FRF, calculated according to eq. 7 along the excitation line, with the FRF of the LTV s-dof system which can be expressed, in the neighborhood of the resonance, as follows:

$$
H(u, \eta)=\frac{S}{-\eta^{2}+\bar{\omega}\left(\omega_{r}(u)\right)^{2}+2 i \xi \eta \bar{\omega}\left(\omega_{r}(u)\right)}
$$

where $S$ is a constant, $\bar{\omega}$ is the natural frequency which is expressed as function of the rotational speed variation with time $\omega_{r}(u)$ in Fig. 10 the blue line represents the WFRF for the case presented in the previous figure. The red line is the best fitting FRF which allows evaluating the damping factor $\xi$ if the system which in this case results $\xi=0.027 \%$ in the present study, the damping factors resulted well below $10 \%$, hence the damping logarithmic decrement $\delta$ is related to the damping factor approximately by $\delta \approx$ $\xi \cdot 2 \pi$.

Thanks to this approach, it is possible to estimate the aggregated damping of the system, meaning the sum of mechanical and aerodynamic contributions to last stage blade damping under steam flow, for different nodal diameters, both for forward and backward travelling wave on the blade row. In Fig.11, measured aggregated damping in terms of logarithmic decrement $\delta$ for the two analyzed operating conditions OP3 and OP8 is reported. Points on the chart represent the averaged value of the damping measurements for each strain gauge installed on the blade. The damping estimation method described above is accurate, but there is some uncertainty in the strain gauges measurement chain: the subsequent analyses to separate mechanical and aerodynamic damping contributions will be carried out considering two $4^{\text {th }}$ order polynomial fitting curves of the log. dec. vs ND function for OP3 and OP8 respectively.

\section{NumericAl ANALYSIS}

\subsection{Computatuional method}

All the numerical analyses have been performed with the RANS/URANS TRAF code [14. The solver has been extended to simulate unsteady flows around vibrating blades, thus implementing an aero-elastic nonlinear method. The non-linear uncoupled method for 


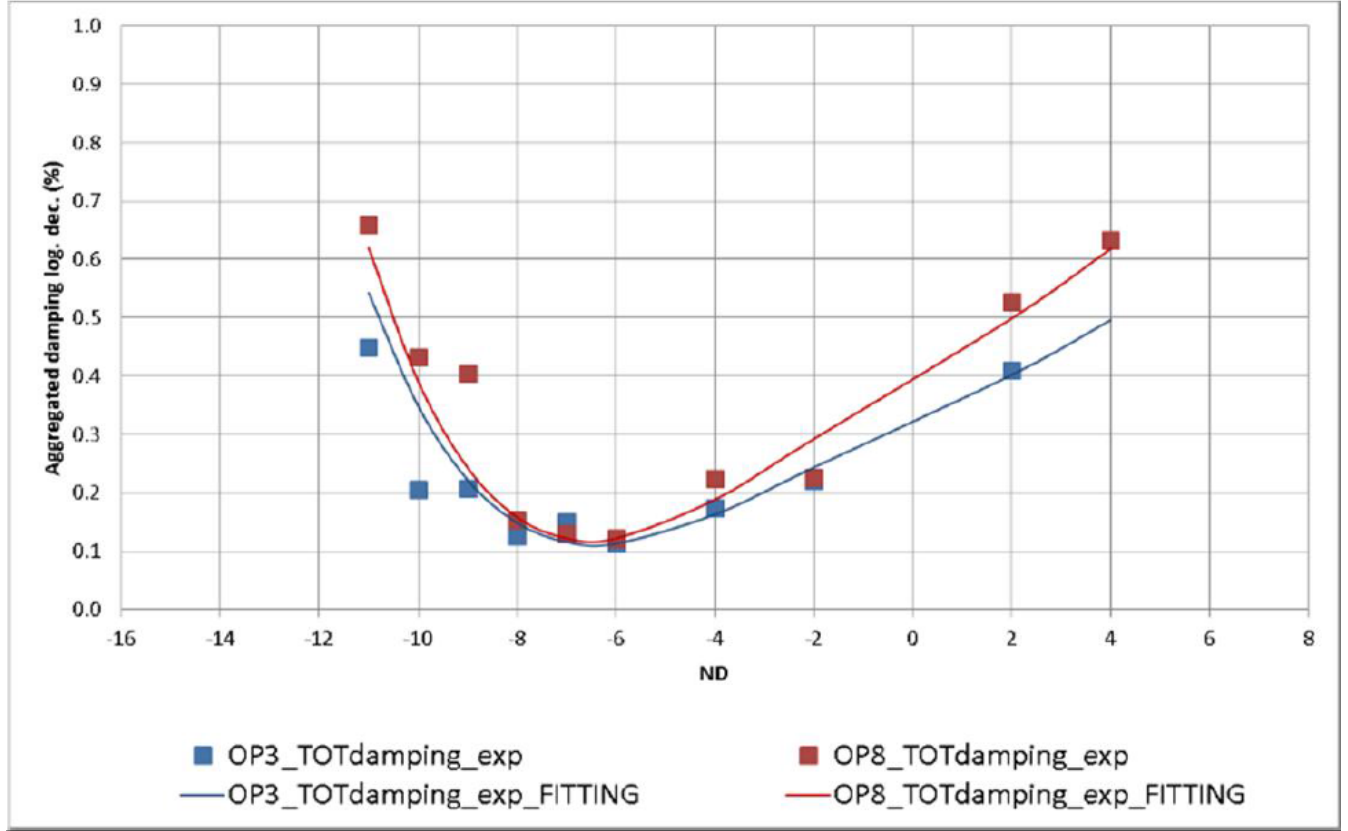

FigURE 11. Aggregated damping of LSB for the first mode shape, in OP3 and OP8.

flutter analysis is here briefly described and a comprehensive method description and validation can be found in [8].

Time-sinusoidal blade surface vibrations coming from modal analysis are assigned to the aero-elastic calculation as input data to actually deform the fluid domain at each time step. The non-linear unsteady flow equations are integrated on the deforming mesh by applying the same dual time-stepping algorithm used for aerodynamic unsteady simulations. Traveling waves are represented on a single-angular-pitch domain by applying phase-lagged conditions to periodicity boundaries.

Since in uncoupled methods blade vibrations are input data, rather than a result of the computation, flutter stability is estimated by checking the sign of the energetic damping coefficient (or of the logarithmic decrement) applied by the fluid onto the blade during one vibration cycle.

A positive logarithmic decrement means that energy is transferred from the blade to the fluid flow and the cascade oscillation is damped, hence a stable configuration. On the contrary, if the log-dec is negative, the unsteady aerodynamic pressure adds energy to the blade motion and the cascade is unstable. The different aero-elastic behavior mainly depends on the local phase shifting between unsteady pressure and blade vibration.

\subsection{SteAdy AND Unsteady CFD ANALYsis}

Off-design operation of low pressure steam turbines is achieved if the inlet mass flow is reduced and/or if condenser pressure is increased at constant rotating speed. This implies a decrease in volume flow at the last stage blade outlet, because, through the mass flow reduction or the outlet pressure increase, large decrease in last stage pressure ratio and enthalpy drop occurs. The losses grow up because the flow incidence angles are increased. Both the isentropic enthalpy drop reduction and the increased losses lead to a decrease of stage specific work produced by the rotor. When such off-design conditions are enhanced, the last stage starts to ventilate and its specific work may become negative. This means that the last stage blade absorbs part of the work produced by the front stages instead of generating work itself, resulting in a pressure and the enthalpy increase instead of a pressure drop on the last stage. This is the case of the two analysed partload operating conditions of the present work, OP3 and OP8. The outlet axial velocity at the last stage blade trailing edge decreases, while the circumferential component of absolute velocity and, consequently, the associated centrifugal force increases. As this phenomenon takes place, flow streamlines cannot satisfy equilibrium between centrifugal and pressure forces, thus causing a flow separation from the hub endwall profiling. In the case of a strong reduction in volume flow, the centrifugal force increases and the region with reverse flow at the last stage blade outlet section expands in radial direction [15].

Steady CFD simulation may suffer from convergence issues when such reverse flow conditions happen on the outlet boundary of the simulation domain. Thanks to a rake of five 5-hole probes assembled on the vane carrier downstream the last stage blade trailing edge, radial height of flow separation at the hub has been estimated thanks to the yaw angle measurement (Fig. 12 left): at $10 \%$ span higher than $90^{\circ}$ yaw angle was detected, indicating a reverse flow in the corresponding region. This estimation has been used to define a region to be removed from the CFD domain as shown in Fig. 12 (right), in order to avoid any reverse flow on 

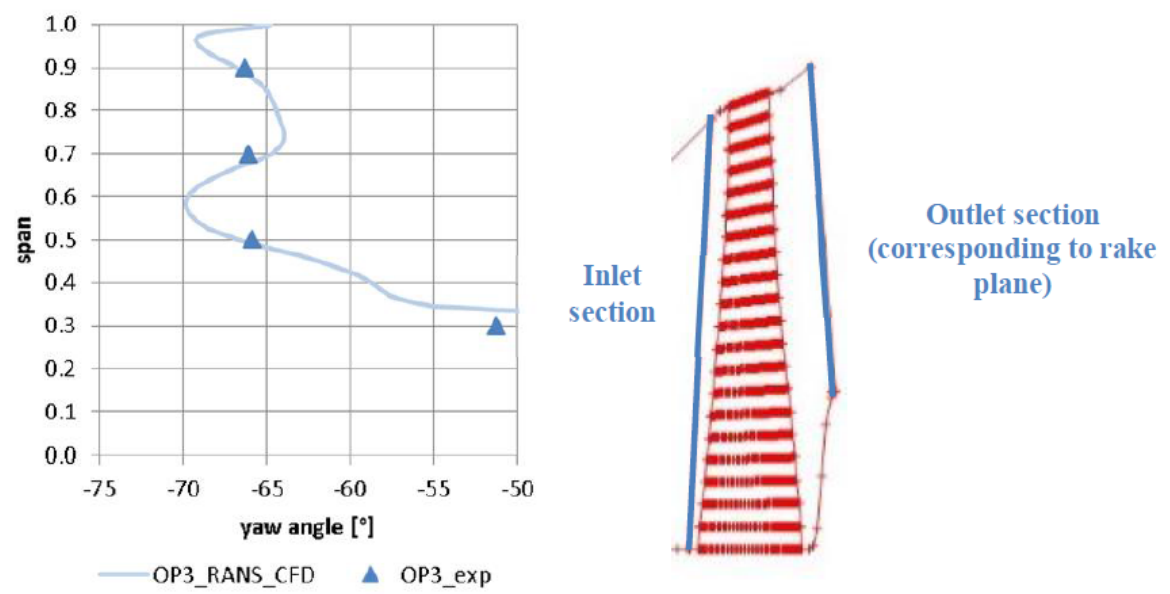

FIGURE 12. Matching of yaw angle measurement at LSB TE in OP3 (left) and meridional view of LSB CFD domain (right).

the outlet boundary and improve simulations convergence. TRAF RANS simulation has been performed using this model and last stage blade loads measured at OP3 and OP8 have been matched. This is important for the subsequent URANS analysis especially on the top of the blade, from mid-span to the tip, where the strongest flow - structure interaction occurs.

TRAF RANS solution has been used to initialize URANS simulations with moving grid for different number of nodal diameters of the first mode-shape family. For each ND, a different mode shape and frequency were assigned, according to results of modal analysis with cyclic symmetry conditions. Each vibration period has been divided in 100 time steps and 20 sub-iterations for each time step have been run. A variable number of periods, generally lower than 15-20, was needed to achieve full convergence and solution periodicity. In the two operating conditions OP3 and OP8, aerodynamic damping (as logarithmic decrement) as a function of number of ND has been achieved as from the plot in Fig. 13.

As described before, the two operating points are characterized by same volume flow rate (i.e. same aerodynamic load on the airfoil), but different mass flow rate: the volume flow rate through the blade channel is the same, but the flow density in OP8 is about $28 \%$ more compared to the one in OP3. This means that, unless strong nonlinearities occur, also aerodynamic damping scales by the same factor. The same kind of flow-structure interaction takes place in the two OPs (which are characterized by same flow Mach number and same blade deformation and frequency), but, as the density of the flow rises, the aero-elastic work exchanged between the flow and blade structure proportionally increases. Reynolds effects related to different values are reasonably considered as second-order for the purpose of this work. Looking at the energetic damping surface density on the airfoil for the ND having minimum aerodynamic damping and comparing OP8 to OP3, it can be noted that the regions characterized by aerodynamic exci- tation (red) or aerodynamic damping (blue) on the airfoil surface are the same. In OP8, the energetic damping intensity is always stronger if compared to OP3 in terms of absolute value, keeping the same sign (Fig.14). Furthermore, it is worth to note that the highest damping/exciting interaction contributing to integral value of logarithmic decrement are located in the upper region of the airfoil, where the highest modal displacements occur.

\subsection{COMPARISON OF NUMERICAL AND EXPERIMENTAL RESULTS}

In 2.3 consistent measurements of aggregated damping in the two different mass flow rate conditions were shown. In 3.2 numerical assessment of the aerodynamic damping for the same conditions was presented.

Experimental data obtained in 3.2 were then used to separate the components of mechanical and aerodynamic damping, using the approach described in [5]. For each ND, results of aggregated damping measured at same volume flow, but different flow density, can be extrapolated to zero mass flow: in fact, without steam flow, the aggregated damping represents actually the mechanical damping of the blade. Assuming constant mechanical damping as the mass flow rate increases, for each ND the difference between the measured aggregated damping and the projected mechanical damping gives the aerodynamic damping for that particular flow condition.

According to the abovementioned approach, it is possible to define if a volume flow condition is inherently stable or not for the last stage blade: as the mass flow increases, if the aggregated damping increases too, the aerodynamic damping is positive and the blade is being operated safely. On the other side, if the aerodynamic damping is negative, as the mass flow grows the aggregated damping will decrease and there will be a limit value of mass flow, corresponding to zero aggregated damping (where negative aerodynamic damping fully overcomes mechanical damping), 


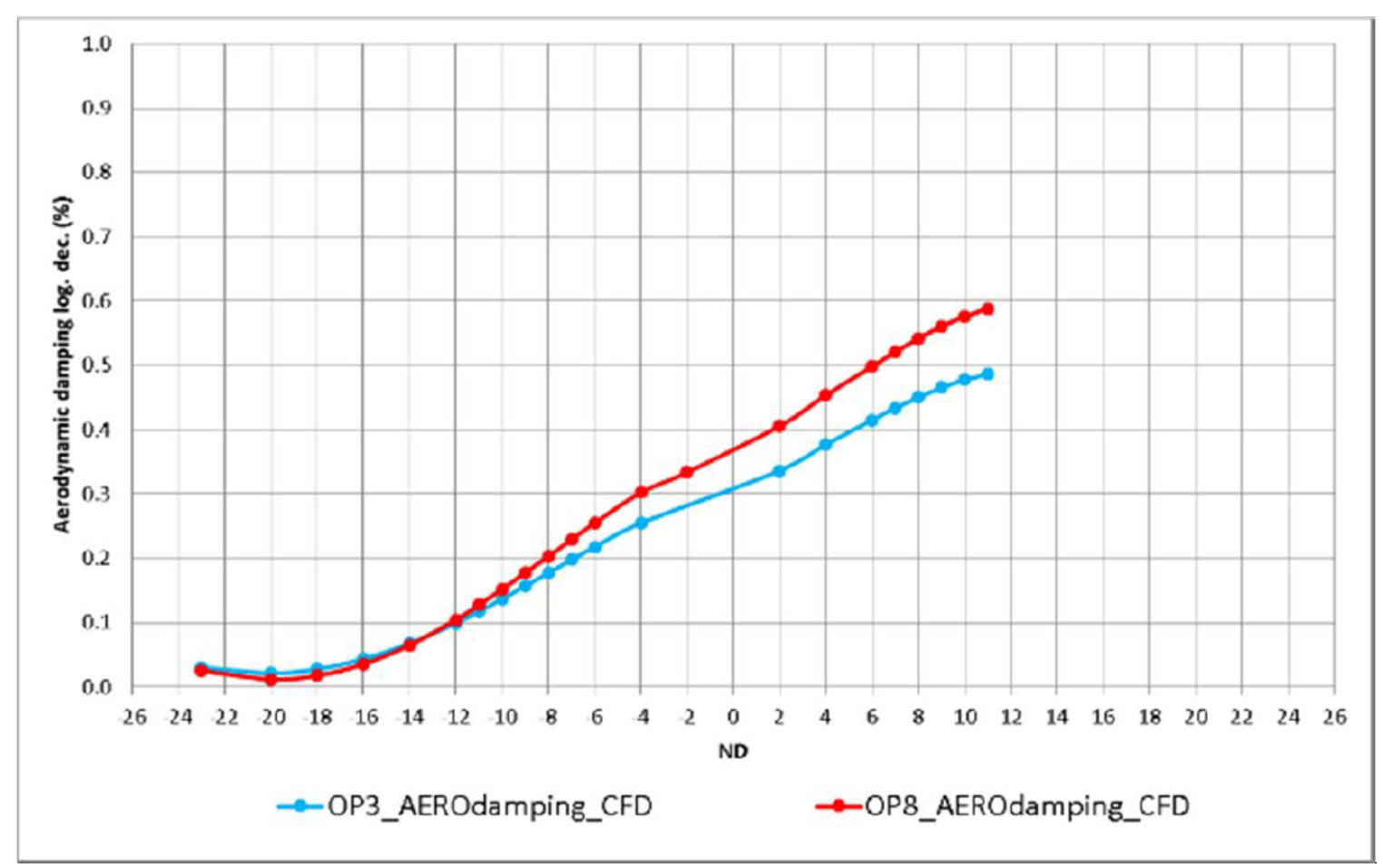

FiguRE 13. Aerodynamic damping (logarithmic decrement) vs ND for the first mode shape in OP3 and OP8, assessed through TRAF URANS simulations.

\section{OP3}

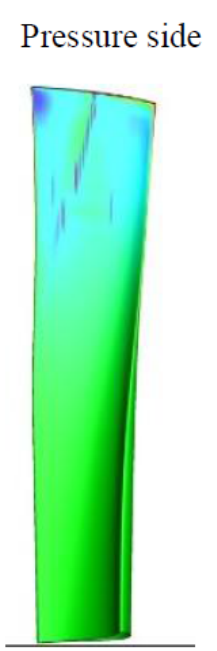

Suction side

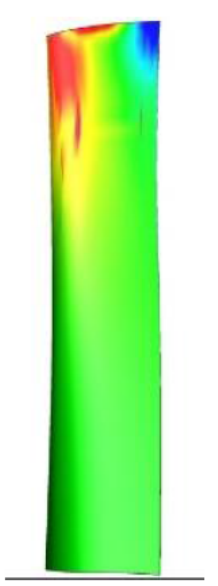

Energetic damping surface density

2.50E-03 2.24E-03 $1.97 \mathrm{E}-03$

$1.71 \mathrm{E}-03$

$1,45 \mathrm{E}-03$

$1.18 \mathrm{E}-03$

$9.21 \mathrm{E}-0.4$

6. $58 \mathrm{E}-04$

3.95E-04

$1,32 \mathrm{E}-04$

$-1.32 \mathrm{E}-04$

$-3.95 \mathrm{E}-04$

-6.58E-04

$9.21 \mathrm{E}-04$

$1,1 \mathrm{BE}-03$

$-1.45 E-03$

$-1.71 \mathrm{E}-03$

$1.97 \mathrm{E}-03$

$-2.24 \mathrm{E}-03$

2.50E 03

\section{OP8}

Pressure side Suction side
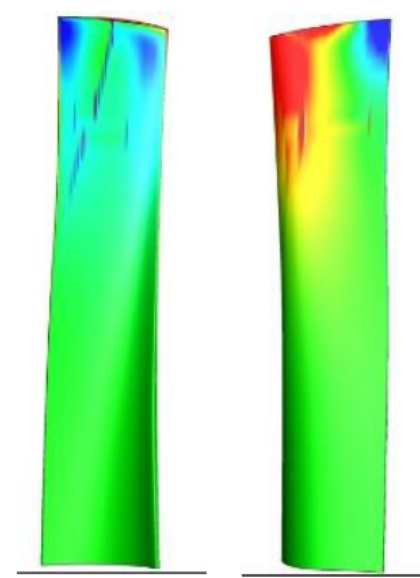

FIgURE 14. Energetic damping surface density for first mode shape, $N D=20$ backward traveling wave, in OP3 and OP8. 


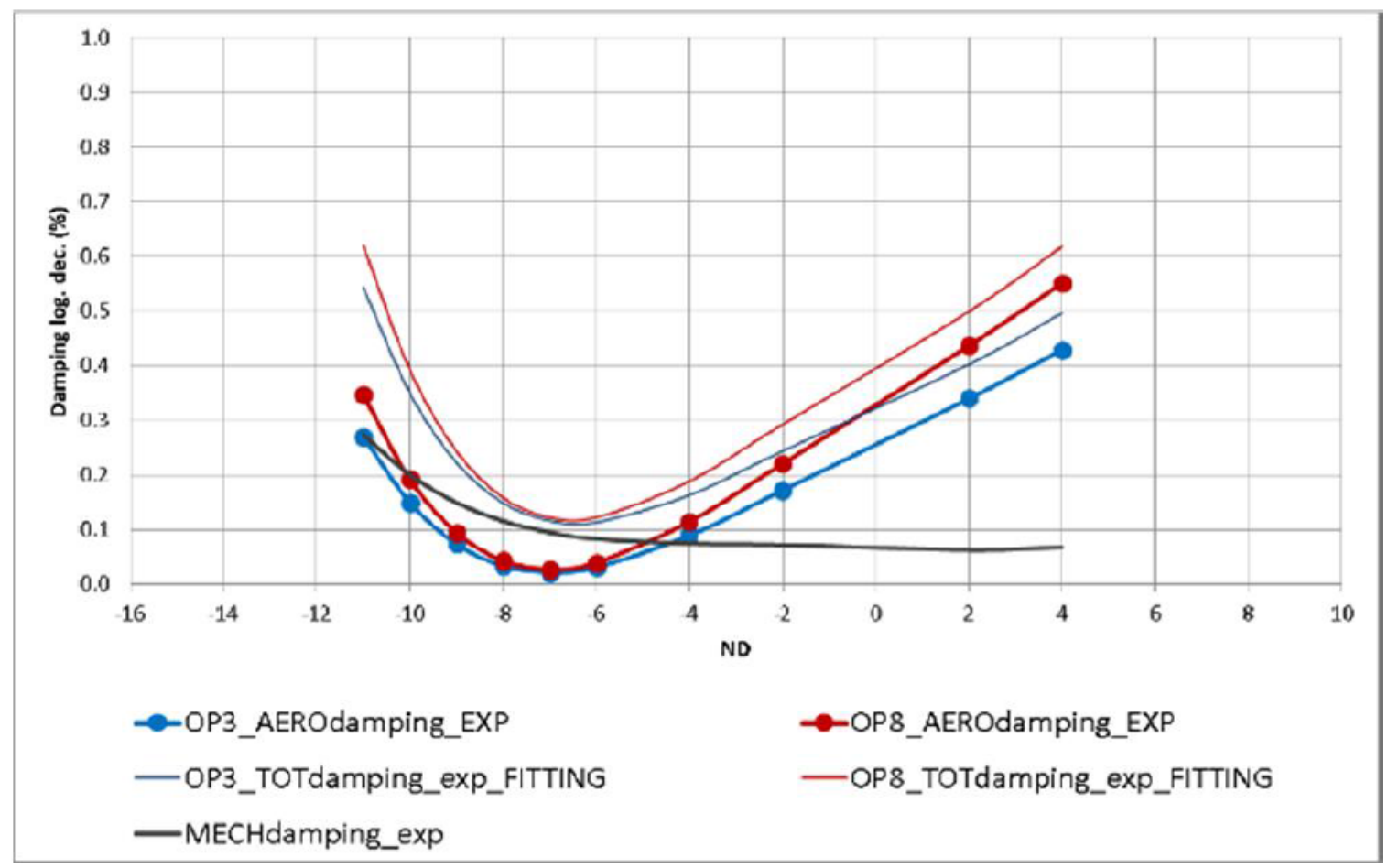

FIGURE 15. Separation of mechanical and aerodynamic contributions for OP3 and OP8, from aggregated damping measurements.

which can be considered as the blade stability margin. This simple linear model relies on the physical behaviour of aerodynamic damping described in 3.2

In Fig. 15 results of projected mechanical damping and estimated aerodynamic damping achieved through this method are reported. Results are obtained from polynomial fitting curves of the aggregated damping measurements.

Mechanical damping is smaller at low ND (about $0.1 \%$ ), while it slightly gets larger at higher ND (almost $0.3 \%$ ). A possible reason of this behaviour is the following: the snubber is designed to have stiff contacts between its suction and pressure sides when the centrifugal force at nominal speed untwists the blade airfoil. As the row vibration has increasing number of ND, also the phase shift between oscillations of adjacent blades increases. This could lead to snubber contact unstiffening, generating friction between the pressure and suction side surfaces, which is the reason of additional mechanical damping. Subtracting mechanical damping from aggregated damping, also aerodynamic damping component as logarithmic decrement was estimated for OP3 and OP8.

In Fig. 16 a comparison between aerodynamic damping estimated from measurements and CFD results is reported. It is worth to note following considerations:

- experimental measurements and numerical methods predict positive aerodynamic damping for both the analysed operating conditions, meaning that the blade is stable with regard to flutter at the corresponding volume flow, in ventilation, for the first mode shape,
- the measured and calculated aerodynamic damping average level is very similar, varying between 0.0 and $0.6 \%$,

- also the minimum aerodynamic damping assessed through TRAF is similar to minimum aerodynamic damping measured on the test plant, and close to $0 \%$,

- the ND corresponding to the minimum aerodynamic damping is different: experimental data have a minimum at $7 \mathrm{ND}$, while numerical results show a minimum at $20 \mathrm{ND}$, both for backward travelling wave. As mentioned in [16], reasons of this discrepancy can be found in some CFD model simplifications, such as missing of snubber modelling. Another reason of this can be the snubber contact modelling in the modal analysis: if the snubber contacts unstiffen, the modal displacements can be affected, with an impact on the blade deformation imposed in the URANS analysis.

\section{Conclusion}

An extensive experimental campaign on a 3-stages downscaled low pressure steam turbine has been carried out at the T10MW test plant, in Plzen, aiming to characterize a snubbered last stage blade flutter behavior at low load conditions.

The rig has been heavily instrumented in order to provide an in-depth characterization of the flow behavior throughout the turbine as well as to measure the structural dynamic response of the LSB.

The overall damping has been evaluated by exciting the blade resonance by means of an $\mathrm{AC}$ magnet 


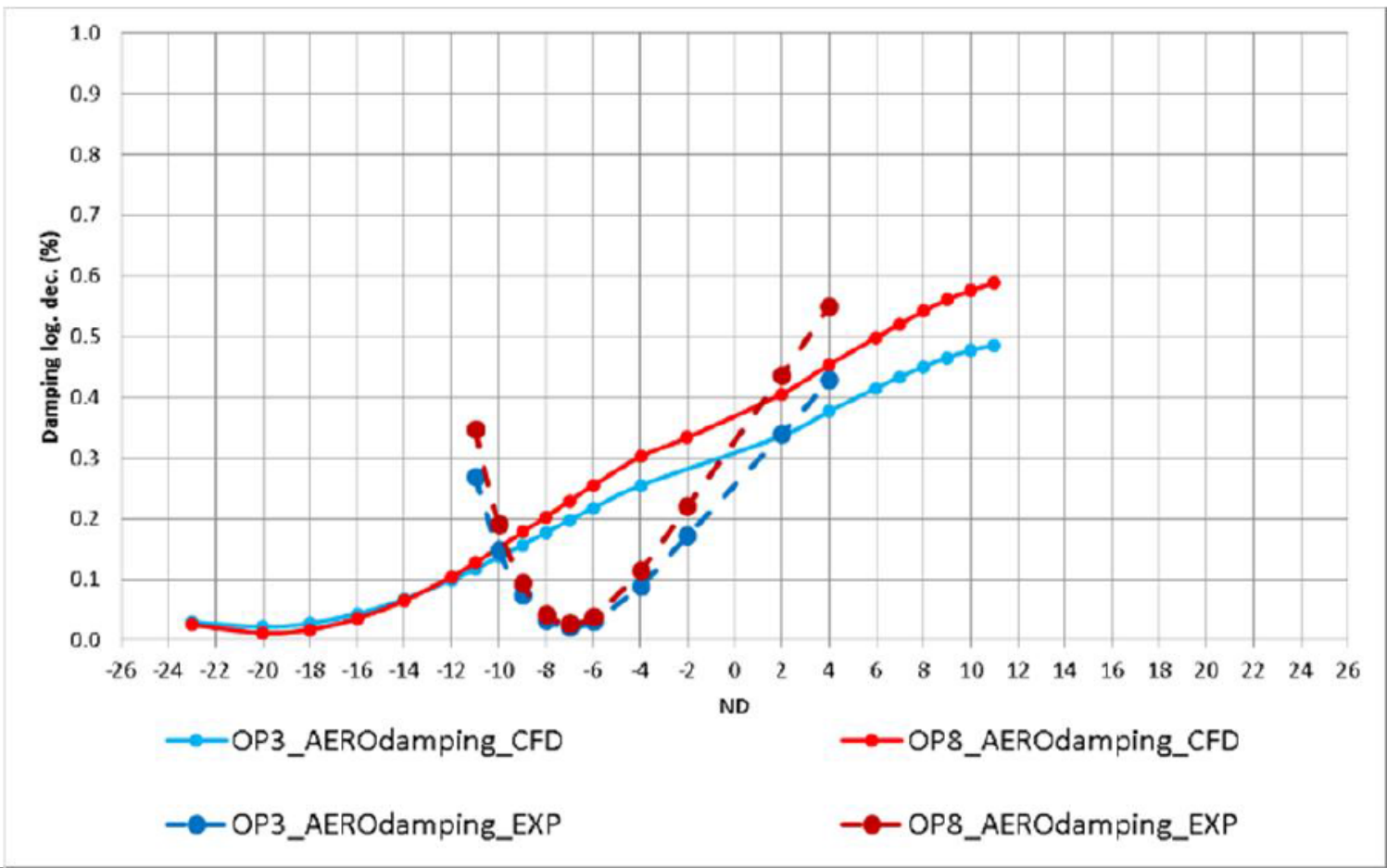

FIGURE 16. Aerodynamic damping in OP3 and OP8: comparison of experimental and numerical results.

mounted on the vane carrier. A dedicated system has been developed to control the magnet excitation frequency as the turbine rotational speed oscillates during tests in order to make the damping estimation procedure more precise. Furthermore, the mechanical and the aerodynamic contribution to the aggregated damping have been separated. A CFD numerical method has been adopted to predict the aerodynamic damping in analogous test conditions. Numerical and experimental results have been discussed and compared.

A satisfying agreement has been found from an industrial point of view, showing that the software tool is capable to properly predict the last stage blade flutter stability at low load condition, even if some discrepancies in results need still to be fixed. Experimental data at very low LSB loads with stronger ventilation are available from the experimental tests and a wider campaign of CFD simulations is currently ongoing to extend the purpose of the present work to stronger part-load regimes.

\section{LIST OF SYMBOLS}

$A E N$ Ansaldo Energia

$D S P W$ Doosan Škoda Power

$T 10 M W$ Experimental test turbine in Plzen

$A C / D C$ Alternating/Direct current

$L S B$ Last stage blade

$L P T$ Low pressure turbine

$N$ Rotation speed

$D$ Characteristic diameter

$p$ Pressure

$v$ Specific volume $f \quad$ Blade eigen-frequency

$C h$ Airfoil real chord

FT FlexTurbine project

$O P$ Operating point

FNS Full Navier-Stokes

$S G$ Strain gauges

$B T T$ Blade tip timing

$N D$ Number of nodal diameters

\section{ACKNOWLEDGEMENTS}

This research work was supported by the European project Flexturbine, H2020 research and innovation programme under grant agreement No. 653941

\section{REFERENCES}

[1] C. Fuhrer, D. M. Vogt. On the impact of simulation approaches on the predicted aerodynamic damping of a low pressure steam turbine rotor. In ASME Turbo Expo 2017: Turbomachinery Technical Conference and Exposition, vol. 8, p. V008T29A007. 2017. DOI:10.1115/GT2017-63401

[2] T. Sun, P. Petrie-Repar, D. Qi. Investigation of tip clearance flow effects on an open 3d steam turbine flutter test case. In ASME Turbo Expo 2017: Turbomachinery Technical Conference and Exposition, vol. 8, p. V008T29A024. 2017. DOI:10.1115/GT2017-64021

[3] F. Vanti, L. Pinelli, F. Poli, A. Arnone. Aeroelastic investigation of turbine blade assemblies: cluster systems and mistuned rows. 2017. DOI:10.29008/ETC2017-144.

[4] M. May, Y. Mauffrey, F. Sicot. Numerical flutter analysis of turbomachinery bladings based on time-linearized, time-spectral and time-accurate simulations. 2011. 
[5] T. Rice, D. Bell, G. Singh. Identification of the stability margin between safe operation and the onset of blade flutter. vol. 131. 2007. DOI:10.1115/GT2007-27462

[6] F. Poli, L. Pinelli, A. Arnone. Aeroelastic stability analysis of a non-rotating annular turbine test rig: a comparison between a linearized and a nonlinear computational method. In 22nd International Congress on Sound and Vibration, (ICSV22). 2015.

[7] O. Pütz, H.-P. Kersken, G. Ashcroft, et al. Comparison of linear and nonlinear frequency domain methods for flutter analysis. In ASME Turbo Expo 2018: Turbomachinery Technical Conference and Exposition, vol. 2C. 2018. DOI:10.1115/GT2018-75626

[8] L. Pinelli, F. Poli, A. Arnone, C. Schipani. A timeaccurate $3 \mathrm{~d}$ method for turbomachinery blade flutter analysis. In 12th International Symposium on Unsteady Aerodynamics, Aeroacoustics and Aeroelasticity of Turbomachines (ISUAAAT), pp. 1-4. 2009.

[9] F. Vanti, L. Pinelli, A. Arnone, et al. Aeroelastic optimization of an industrial compressor rotor blade geometry. In ASME Turbo Expo 2018: Turbomachinery Technical Conference and Exposition, vol. 2D, p. V02DT46A016. 2018. DOI:10.1115/GT2018-76474

[10] L. Carassale, M. Marre-Brunenghi, S. Patrone. Estimation of damping for turbine blades in non-stationary working conditions. In ASME Turbo Expo 2015: Turbomachinery Technical Conference and Exposition, vol. 7B, p. V07BT32A018. 2015. DOI:10.1115/GT2015-42945
[11] L. Carassale, M. Marre-Brunenghi, S. Patrone. Modal identification of dynamically coupled bladed disks in runup tests. In ASME Turbo Expo 2016: Turbomachinery Technical Conference and Exposition, vol. 7A, p. V07AT32A018. 2016. DOI:10.1115/GT2016-57251

[12] L. Carassale, M. Marre-Brunenghi, S. Patrone. Wavelet-based identification of rotor blades in passage-through-resonance tests. Mechanical Systems and Signal Processing 98:124 - 138, 2018. DOI:10.1016/j.ymssp.2017.04.023

[13] S. Mallat. A Wavelet Tour of Signal Processing: The sparse way. 2008.

[14] A. Arnone, M. Marconcini, A. Scotti Del Greco, E. Spano. Numerical investigation of three-dimensional clocking effects in a low pressure turbine. Journal of Turbomachinery 126:375-384, 2004. DOI:10.1115/1.1740780

[15] M. Petrovic, A. Wiedermann, S. M. Nedeljkovic, M. Banjac. Part load behavior of the lp part of an industrial gas turbine. p. V02AT40A033. 2017. DOI:10.1115/GT2017-64778 